\title{
Ethos e criminalidade: análise discursiva de tentativas de extorsão*
}

\author{
Ethos and criminality: discursive analysis of extortion attempts \\ Welton Pereira e Silva \\ Universidade Federal do Rio de Janeiro, Rio de Janeiro, Rio de Janeiro, Brasil.
}

$\diamond$

Resumo: O presente artigo tem por finalidade analisar os ethé discursivos construídos pelos sujeitos comunicantes na situação de comunicação conhecida como Golpe do Falso Sequestro. Para que nosso objetivo fosse alcançado, fizemos a análise do corpus, constituído por três gravações telefônicas de golpes do falso sequestro, baseando-nos nos estudos de Maingueneau (2008), Amossy (2005) e Charaudeau (2012, 2015), bem como em alguns teóricos da Linguística Forense, como Coulthard \& Johnson (2007), Olsson (2008) e Souza-Silva (2009). Após a nossa análise, notamos que os sujeitos que se passam por sequestradores tentam construir para si determinados ethé que corroboram os argumentos por eles utilizados no processo interacional. $\mathrm{Na}$ medida em que os argumentos constituem-se, principalmente, de intimidações e ameaças, os ethé construídos são, frequentemente, o de alguém cruel e disposto a cumprir com suas ameaças, ou seja, o ethos de potência subsidiado por certos imaginários sociodiscursivos acerca da criminalidade.

Palavras-chave: ethos discursivo; argumentação; criminalidade; linguística forense.

\begin{abstract}
This paper aims to analyze the discursive ethe built by the subjects at the communicative situation known as "Fake Kidnapping Scam". To accomplish our goal, we made the analysis of the corpus, that is constituted by three recordings of "Fake Kidnapping Scams", using the studies of Maingueneau (2008), Amossy (2005) and Charaudeau (2012; 2015), as well in some researchers of Forensic Linguistics, as Coulthard \& Johnson (2007), Olsson (2008) and Souza-Silva (2009). After our analysis, we noticed that the fake kidnappers tries to construct to themselves some ethé which corroborates the arguments used by them on the interactional process. To the extent that the arguments are constituted, mainly, by intimidations and threats, the ethé built are of someone cruel and prepared to fulfill their threats: it is the ethos of potence subsidized about certain sociodiscursive imaginaries about criminality.
\end{abstract}

Keywords: discursive ethos; argumentation; criminality; forensic linguistics.

\footnotetext{
* Este artigo diz respeito a uma parte da nossa dissertação de mestrado defendida na Universidade Federal de Viçosa e orientada pela Professora Doutora Mônica Santos de Souza Melo. A pesquisa contou com o apoio da Capes e intitulou-se: "A argumentação em crimes via telefone sob a perspectiva da Teoria Semiolinguística".
} 


\section{Introdução}

A noção de ethos é entendida atualmente, nas ciências da linguagem, como a imagem de si que o sujeito constrói em seu discurso no momento da enunciação. Dessa forma, aquilo que dizemos e a maneira como nos portamos são conteúdos determinantes para a imagem que queremos passar de nós mesmos para outrem. O ethos discursivo, assim, acaba por ser inerente a todo processo de comunicação que envolve o ato de enunciar, no sentido dado por Benveniste (1989).

Partindo desse postulado inicial, o presente artigo tem por finalidade analisar os ethé construídos pelos sujeitos comunicantes em algumas gravações de golpes do falso sequestro. Nossa hipótese é a de que, através da construção de um ethos intimidador, perigoso e, até mesmo, relativamente honesto, os sujeitos comunicantes conseguem corroborar seus argumentos na tentativa de torná-los mais eficientes. O sujeito comunicante seria o ser social, empírico, que projeta no discurso uma imagem discursiva através do sujeito enunciador, o ser de fala (CHARAUDEAU, 2012).

Para comprovar nossa hipótese, partimos da Teoria Semiolinguística do Discurso, de Patrick Charaudeau, bem como dos estudos a respeito do ethos discursivo encontrados em alguns autores, tais como Maingueneau (2008) e Amossy (2005). Na primeira seção de nosso artigo, trazemos uma explanação a respeito da noção do ethos na análise do discurso, já que esse conceito surgiu na filosofia aristotélica e foi, recentemente, recuperado pela AD. Posteriormente, discorremos a respeito da Linguística Forense e, por fim, fazemos algumas análises dos ethé construídos pelos sujeitos comunicantes a partir do nosso corpus de pesquisa.

\section{O ethos na Análise do Discurso}

A palavra ethos é oriunda do grego (ท́ $\theta$ os) e significa algo como o modo de ser, o caráter de alguém. Para o filósofo grego, Aristóteles, o ethos constituía uma das provas artísticas da Retórica, ao lado do pathos e do logos. É justamente no livro intitulado A Retórica que o termo é desenvolvido pelo filósofo, que considera o caráter demonstrado pelo orador como um fator crucial para que a plateia, o público alvo da persuasão, sinta-se inclinada a acreditar em suas palavras:

Persuade-se pelo carácter quando o discurso é proferido de tal maneira que deixa a impressão de o orador ser digno de fé. Pois acreditamos mais e bem mais depressa em pessoas honestas, em todas as coisas em geral, mas sobretudo nas de que não há conhecimento exacto e que deixam margem para dúvida. É, porém, necessário que esta confiança seja resultado do discurso e não de uma opinião prévia sobre o carácter do orador; pois não se deve considerar sem importância para a persuasão a probidade do que fala, como aliás alguns autores desta arte propõem, mas quase se poderia dizer que o carácter é o principal meio de persuasão (ARISTÓTELES, 2005, p.96).

Como podemos notar, para o filósofo, o caráter do orador constitui um forte aparato para os argumentos desenvolvidos no processo de persuasão. Através daquilo que é dito e da maneira como é dito, se o caráter demonstrado pelo orador é o de alguém prudente, virtuoso e benevolente (p. 160), o público tende a confiar mais em suas palavras. Ao lado do caráter de pessoa detentora das características supracitadas, Aristóteles enumera dois outros modos de persuasão que estão associadas ao ethos: o pathos, que se configura na disposição dos ouvintes em relação ao orador, aos sentimentos, às paixões que esse pode despertar no auditório; e o próprio $\log o s$, que se configura no discurso em si e na utilização de provas lógicas na argumentação. Para Aristóteles:

Muito conta para a persuasão, sobretudo nas deliberações e, naturalmente, nos processos judiciais, a forma como o orador se apresenta e como dá a entender as suas disposições aos ouvintes, de modo a fazer que, da parte destes, também haja um determinado estado de espírito em relação ao orador (ARISTÓTELES, 2005, p. 159).

Dessa forma, ao tentar persuadir o seu público, o orador deve procurar cativar esse mesmo público. Essa noção foi trabalhada por Perelman \& Tyteca (2005) que, ao lançarem uma nova proposta de estudo sobre a arte retórica, defendem que a adesão do público às ideias expostas pela argumentação é um dos principais objetivos do orador. Para os postulantes da Nova Retórica, "O objetivo de toda argumentação (...) é provocar ou aumentar a adesão dos espíritos às teses que se apresentam a seu assentimento" (p. 50). Desse modo, as estratégias argumentativas e discursivas que levam à criação de determinadas imagens de si apresentadas pelo sujeito comunicante são essenciais para uma argumentação eficaz.

Vemos, então, que, para Aristóteles, o que é dito pelo orador e a maneira como ele se apresenta são fatores cruciais para que o público dê credibilidade aos argumentos por ele utilizados. No entanto, os pensadores romanos detinham uma ideia diferente a esse respeito. Para eles, o caráter do orador era mais consolidado a partir de sua história de vida, do posicionamento social deste e de sua linhagem do que apenas daquilo que é dito. De acordo com Amossy: 
$\mathrm{Na}$ arte oratória romana, inspirada mais em Isócrates (436-338 a.C.) que em Aristóteles, o ethos pertence à esfera do caráter. Segundo Quintiliano, o argumento exposto pela vida de um homem tem mais peso que suas palavras. E Cícero define o bom orador como o vir boni dicendi peritus, um homem que une ao caráter moral a capacidade de bem manejar o verbo (AMOSSY, 2005, p. 17-18).

Para os pensadores romanos, portanto, o ethos é, na verdade, o modo de vida, os exemplos concretos dados pelo orador e não apenas aquilo que ele diz. É o "homem bom, perito no dizer", nas palavras do próprio Cícero. Esse pensamento de que as questões situadas fora do dizer propriamente dito ajudam na (ou definem a) construção da imagem do orador foi aproveitado, posteriormente, por Maingueneau (2008), que nos apresenta a noção do ethos pré-discursivo, ou seja, a imagem que o público destinatário tem do locutor antes que ele profira seu discurso.

Já na atualidade, a Análise do Discurso, nomeadamente a de linha francesa, tem se preocupado com a questão do ethos na medida em que é na prática discursiva que a imagem de si é construída. Diante disso, Dominique Maingueneau trata, em alguns trabalhos, acerca dos ethé discursivos construídos na enunciação. A respeito desta última noção, seguindo a tradição benvenistiana, neste trabalho, entendemos que "a enunciação é este colocar em funcionamento a língua por um ato individual de utilização" (BENVENISTE, 1989, p. 82).

Maingueneau (2008) nos fala a respeito da noção de ethos pré-discursivo, que seria a imagem que o público destinatário faz do enunciador antes que ele profira o seu enunciado. Nota-se que essa noção está fortemente relacionada ao que os filósofos romanos concebiam a respeito dos ethé. O linguista também nos apresenta a noção de ethos dividida entre ethos mostrado e ethos dito. Conforme ele nos explica:

O ethos de um discurso resulta da interação de diversos fatores: ethos pré-discursivo, ethos discursivo (ethos mostrado), mas também os fragmentos do texto nos quais o enunciador evoca sua própria enunciação (ethos dito) - diretamente ("é um amigo que lhes fala") ou indiretamente, por meio de metáforas ou de alusões a outras cenas de fala, por exemplo. A distinção entre ethos dito e mostrado se inscreve nos extremos de uma linha contínua, uma vez que é impossível definir uma fronteira nítida entre o "dito" sugerido e o puramente "mostrado" pela enunciação (MAINGUENEAU, 2008, p. 18).

Como podemos ver, a distinção entre o ethos dito e mostrado não é tão clara, no entanto, podemos entender o ethos dito como a explicitação propriamente dita da imagem de si que o enunciador deseja construir em seu discurso, enquanto que o ethos mostrado seria a construção dessa imagem pautada em aspectos como o tom de voz, o conteúdo do enunciado etc. Para facilitar a compreensão dessas noções, que se relacionam e se complementam, apoiadas em estereótipos compartilhados em sociedade, Maingueneau (2008) nos apresenta o seguinte esquema:

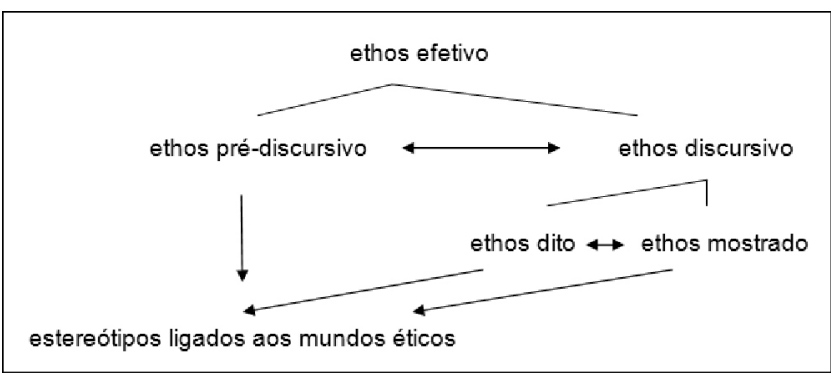

Figura 1. As diferentes instâncias do ethos

Fonte: Adaptado de Maingueneau (2008, p. 19)

Outra pesquisadora que se debruça sobre o estudo do ethos discursivo é Ruth Amossy, que também estuda a questão dos estereótipos, estes últimos entendidos como representações coletivas e cristalizadas. No presente trabalho, preferimos fazer uso do conceito de "imaginários sociodiscursivos" ao de "estereótipo", adotado tanto por Maingueneau (2008) quanto por Amossy (2005), já que nos afiliamos à Semiolinguística do Discurso. Para Charaudeau:

Será entendido que nossa proposta consiste em se livrar de uma noção, o estereótipo, que é muito restritiva, uma vez que é reconhecida pelo seu caráter de vinculação a uma verdade que não será averiguada ou que seria falsa. $\mathrm{O}$ imaginário não é nem verdadeiro nem falso. Ele é uma proposta de visão do mundo que se apoia sobre alguns saberes que constroem sistemas de pensamento, que podem se excluir ou se sobrepor uns aos outros. Isso permite que o analista não tenha que denunciar este ou aquele imaginário como falso (CHARAUDEAU, 2007, p. 08. Tradução nossa). ${ }^{1}$

Tanto os estereótipos quanto os imaginários sociodiscursivos funcionam como uma base sobre a qual os destinatários do enunciado se apoiam para "captar" e construir uma imagem do enunciador. Dito de outra

\footnotetext{
1 On l'aura compris, notre proposition consiste à se débarrasser d'une notion, le stéréotype, qui est par trop restrictive puisqu'elle n'est repérable que par son caractère de fixation d'une vérité qui ne serait pas avérée, voire qui serait fausse. L'imaginaire n'est ni vrai ni faux. Il est une proposition de vision du monde qui s'appuie sur des savoirs qui construisent des systèmes de pensée, lesquels peuvent s'exclure ou se superposer les uns les autres. Cela permet à l'analyste de ne pas avoir à dénoncer tel ou tel imaginaire comme faux.
} 
forma, o enunciador, por exemplo, constrói para si a imagem de alguém benevolente que será entendida pelos destinatários se estes entenderem o discurso (ou ações) do enunciador como compatíveis àquilo que eles relacionam a "benevolente" em seu universo de conhecimento.

Em nosso corpus, observamos que os sujeitos que se passam por sequestradores se valem de determinados imaginários sociodiscursivos acerca das noções de "crime" e "criminalidade" para construir os ethé desejados. Tais análises são encontradas na seção três. Antes, porém, faz-se necessário discorrer acerca de nosso corpus de análise, que insere este trabalho no âmbito da Linguística Forense.

\section{O corpus e a Linguística Forense}

No presente estudo, propomo-nos a analisar três gravações telefônicas interceptadas e divulgadas pela Polícia Civil do Rio de Janeiro. Os áudios, conseguidos e publicizados pela Revista Veja, faziam parte de uma reportagem especial que não se encontra mais online. Para otimizar o trabalho, realizamos a transcrição do material sonoro, observando, na medida do possível, algumas marcas de oralidade que poderiam contribuir para a construção e manutenção de certos ethé discursivos. Dessa forma, determinadas idiossincrasias linguisticodiscursivas, como a pronúncia de determinados vocábulos de acordo com a norma de algum dialeto ou socioleto específico, foram mantidas.

A análise foi realizada a partir dos postulados teóricos e metodológicos da Teoria Semiolinguística do Discurso, de Patrick Charaudeau. Além dessa, lançamos mão, também, de alguns conceitos de Maingueneau (2008). No entanto, visto nosso corpus ser oriundo de uma situação de comunicação considerada desviante, criminosa, no caso, uma tentativa de extorsão veiculada pelo telefone, é importante nos posicionarmos em uma área da Linguística Aplicada que apenas começa a ganhar espaço nas universidades brasileiras: a Linguística Forense.

Desde a Antiguidade, foi notado que certas marcas dialetais serviriam para relacionar alguns falantes a determinados grupos. De igual modo, a atribuição de autoria a textos apócrifos foi, e continua sendo, preocupação de estudos em diversas áreas, como a Filologia. A partir da década de setenta, no entanto, vêm surgindo diversas publicações de linguistas que se preocupam em analisar a linguagem como evidência, ou mesmo, buscam mais bem compreender o discurso utilizado no interior de práticas judiciais. Estamos nos referindo à Linguística Forense que, de acordo com Olsson (2008): é a aplicação do conhecimento linguístico a um ambiente social particular, nomeadamente o fórum (é daí que provém a palavra forense). Em sentido mais amplo, podemos dizer que a Linguística Forense é a interface entre linguagem, crime e lei, onde lei inclui a aplicação da lei, a matéria jurídica, a legislação, disputas ou procedimentos legais, e até mesmo disputas que só envolvem potencialmente alguma infração da lei ou alguma necessidade de encontrar uma solução legal (OLSSON, 2008, p. 03. Tradução nossa. Grifo nosso). ${ }^{2}$

Na medida em que nos propomos, no presente artigo, a analisar os diferentes ethé discursivos construídos pelos sujeitos comunicantes em golpes do falso sequestro, ação tipificada como tentativa de crime de extorsão, nossa pesquisa se situa no escopo da Linguística Forense. A partir da descrição e análise da construção, manutenção ou desconstrução de determinadas imagens discursivas, é possível compreender de forma mais aprofundada as interações efetuadas no interior dessa prática discursiva, o que poderia auxiliar na elaboração de políticas de segurança pública que busquem o combate a tais crimes ou, pelo menos, a prevenção de sua consumação.

A noção de Linguística Forense, entretanto, apresenta duas facetas. Por um lado, diz respeito ao estudo da linguagem enquanto evidência em uma demanda judicial; por outro, diz respeito a todo estudo que se debruce sobre algum discurso realizado no interior de práticas judiciais, legais, ou mesmo possivelmente criminosas, tal como nos ensina Olsson (2008).

\section{Ethé vinculados à criminalidade em golpes do falso sequestro}

Os golpes do falso sequestro são uma espécie de crime de extorsão na qual um indivíduo liga para um número aleatório de celular e se passa por um sequestrador em posse de algum parente da pessoa que atendeu o telefonema. Essas ligações são normalmente feitas do interior de presídios e costumam ser realizadas durante a madrugada (RODRIGUES, 2007). O nosso corpus de pesquisa consiste em três gravações de golpes do falso sequestro conseguidas e disponibilizadas pela revista Veja na modalidade online. Pelo fato de apresentarem identidades características, finalidade e temas particulares, tais interações são consideradas um gênero do discurso, conforme atestamos em Silva e Melo (2015).

Como dissemos anteriormente, estamos partindo do pressuposto de que a construção de determinados ethé discursivos serve para corroborar os argumentos utilizados pelos sujeitos comunicantes a fim de fazer com que esses sejam mais eficazes. Como nos lembra Dascal (2005), não podemos falar que o ethos discursivo 
constitui uma prova no sentido argumentativo, no entanto, os argumentos "ethóticos", para pegarmos emprestado o termo do autor, podem ser entendidos como a capacidade de fazer com que o público destinatário se incline a aceitar os argumentos do orador.

Podemos entender essa prática de linguagem através do contrato comunicativo proposto por Charaudeau, afinal, o orador constrói para si um ethos adequado à situação de comunicação para tentar convencer o seu destinatário. Dessa forma, ele faz uso das visadas discursivas (CHARAUDEAU, 2012) de fazer-crer para fazer-fazer. $\mathrm{Na}$ análise do excerto abaixo, essa questão ficará mais bem esclarecida:

\section{Excerto I}

Suposto Sequestrador: A sua filha, na verdade, não foi acidentada, ela tá com a gente, ela foi vítima de um sequestro. Se a senhora tentar chamar o seu marido, ou desligar o telefone, a gente vai tocar fogo na sua filha viva! É isso que a senhora quer?

Vítima: Não

Suposto Sequestrador: Ela está dentro de um cativeiro, amarrada e amordaçada, chorando muito. Ela deu o seu número dizendo que a senhora estava disposta a ajudar. Se a senhora tentar chamar seu marido, ou tentar desligar o telefone, a gente vai tacar gasolina e tocar fogo nela, tá me entendendo?

Esse trecho foi retirado de uma interação que se iniciou com o suposto sequestrador passando-se por um tenente da polícia militar, dizendo que a filha da vítima havia sofrido um acidente. Após obter a informação a respeito do nome da filha, e depois de a vítima dizer que irá chamar o seu marido, o sujeito comunicante do golpe anuncia o sequestro.

É importante destacar que, como nos alerta Rodrigues (2007), a maior parte das ligações telefônicas de golpes do falso sequestro é feita do interior de presídios por um ou dois sujeitos encarcerados. No entanto, nessa interação, o sujeito comunicante constrói para si um ethos coletivo, através do uso da locução pronominal "a gente", dizendo a todo o momento que ele e mais algumas pessoas (uma suposta gangue) colocariam fogo na filha sequestrada. Estamos diante de um imaginário sociodiscursivo relacionado à criminalidade urbana, na qual agem diversos grupos e facções.

Além disso, o ethos mostrado é o de alguém que não se importa em cometer um sequestro ou um assassinato, ou seja, o sujeito constrói para si a imagem de alguém cruel, impiedoso e capaz de cumprir com suas ameaças, logo, constrói um ethos de potência, na terminologia de Charaudeau (2015). É importante frisar que Charaudeau (2015) nos fornece uma nomenclatura apropriada aos seus estudos concernentes ao Discurso Político. Entretanto, salvaguardadas algumas diferenças relativas à situação e às identidades dos sujeitos que dela participam, esses termos podem ser aplicados aos discursos por nós analisados. Afinal, através do ethos de potência, o enunciador procura demonstrar que detém o poder necessário para cumprir sua palavra, seja uma promessa eleitoral ou uma ameaça.

No excerto analisado, esse ethos é construído através da utilização de argumentos pautados em ameaças, como "se a senhora tentar chamar seu marido, ou tentar desligar o telefone, a gente vai tacar gasolina e tocar fogo nela (...)", que evocam uma situação de terror com a intenção de despertar determinados sentimentos na vítima. É a questão do pathos, ou seja, da capacidade que certos enunciados apresentam de levar o destinatário a experienciar determinadas emoções. Visto ser este trabalho destinado à análise da instância do ethos, entretanto, não entraremos em pormenores teóricos acerca do pathos.

Como podemos observar, certos elementos do enunciado acima contribuem para a construção da imagem de um sequestrador cruel por parte da vítima. Elementos lexicais como "cativeiro", "amarrada" e "amordaçada" remetem ao campo semântico da violência e da criminalidade, referência que pode ser feita pela vítima a partir dos imaginários sociodiscursivos que ela compartilha com sua comunidade.

O mesmo acontece no segundo excerto analisado:

\section{Excerto II \\ Suposto Sequestrador: Ela é a filha da senhora, não é? Vítima: É! \\ Suposto Sequestrador: Ela foi vítima de um assalto, trouxemos ela pro interior de uma favela. Estamos ligando pra tentar resolver e negociar a vida dela da melhor maneira possível. Até porque ela mesma implorou pela própria vida e que fizesse essa ligação pra senhora. Peço que mantenha a calma, não envolva qualquer tipo de pessoa pra não ter nenhum agravante na vida da sua filha. Nosso objetivo é ajudar e soltar sua filha com vida!}

Essa tentativa de extorsão iniciou-se com um sujeito comunicante chamando pela mãe em tom de choro. Assim que a vítima dá uma informação a respeito de um parente (ela perguntou se era sua filha, mesmo sendo uma voz masculina), um segundo sujeito toma o turno e se apresenta também como um grupo de criminosos ao fazer uso do pronome "nós" através dos verbos "trouxemos" e "estamos", bem como do uso do possessivo "nosso".

Novamente, o ethos coletivo, amparado em certos imaginários sociodiscursivos, é construído no intuito de corroborar a cena enunciativa proposta. Nessa segunda interação analisada, no entanto, o suposto sequestrador tenta construir para si o ethos mostrado de alguém (ou um grupo) até certo ponto benevolente, misericordioso. 
Afinal, pelo fato de a suposta sequestrada ter implorado pela sua própria vida, eles estão ligando para "tentar resolver e negociar a vida dela da melhor maneira possível". Assim, através da construção de um ethos de virtude (CHARAUDEAU, 2015), o sujeito comunicante procura deixar claro que o objetivo do grupo é ajudar e soltar a filha da vítima com vida.

Apesar de romper com o princípio lógico da não contradição, esses argumentos podem ter sido utilizados com a finalidade de fazer com que a vítima acreditasse que os sujeitos queriam o bem para a sua filha (fazercrer), dessa forma, levando-a a contribuir com os supostos sequestradores, efetuando o pagamento do falso resgate (fazer-fazer). No entanto, a vítima, não estando em condições cognitivas de efetuar a negociação, não age com a tranquilidade esperada, fazendo com que os sujeitos mudem seu discurso e, consequentemente, desconstruam o ethos anteriormente construído e acabem por revelar outra imagem discursiva:

\section{Excerto III \\ Vítima: Não é negociar, eu não tenho nada! Só quero que você ponha o telefone nela. Eu sou uma faxineira, faxineira! \\ Suposto Sequestrador: Tá disposta a negociar? \\ Vítima: Eu quero! \\ Suposto Sequestrador: Eu vou matar a filha dela... Pode começar a tocar fogo na filha dela}

Notamos que, para convencer a vítima a efetuar o pagamento do resgate, o suposto sequestrador diz claramente que ele mesmo cometerá o assassinato e, no enunciado seguinte, dá ordens explícitas para que os supostos membros do grupo de sequestradores comecem a "tocar fogo" na filha da vítima. Houve, portanto, a desconstrução do ethos de virtude, de alguém benevolente, para, agora, ser construída a imagem de alguém cruel que não será mais misericordioso, como havia dito antes.

É importante salientar que a pessoa que atendeu o telefonema, por sua vez, constrói para si um ethos dito de vítima ao dizer explicitamente, chegando a repetir de forma mais enfática, representado na transcrição pelo sublinhado, a sua profissão (faxineira). Tal enunciado remete a um imaginário sociodiscursivo que diz que, ao menos no Brasil, as profissões relacionadas à limpeza são efetuadas, na maior parte das vezes, por pessoas pertencentes às camadas sociais de menor poder aquisitivo.

Além da menção à sua profissão, a vítima também produz o enunciado "eu não tenho nada", chegando a elevar a voz ao pronunciar as duas últimas palavras, construindo o ethos dito de alguém vitimizado, que não detém os recursos financeiros necessários para efetuar o pagamento exigido pelos supostos sequestradores. Em artigo recente, pudemos demonstrar a forma como alguns aspectos suprassegmentais, como a intensidade da elocução, podem contribuir para a construção de determinados ethé discursivos (cf. SILVA; MELO; VALE, 2017).

No último excerto analisado no presente artigo, o sujeito comunicante que realiza a ligação imita a voz de um homem chorando, dizendo ter sido sequestrado. $\mathrm{Na}$ interação, ele se dirige à pessoa que atendeu o telefonema, chamando-a de "mãe". Diante disso, a vítima pergunta se era a sua filha, chamando-a pelo nome e, nesse ponto, um segundo homem começa a conversar com a vítima.

Em um primeiro momento, o sujeito comunicante tenta construir para si a imagem de alguém que está querendo negociar o pagamento do resgate para que a suposta sequestrada não saísse ferida da situação. Ele tenta, então, construir para si a imagem de alguém confiável, ou seja, um ethos de virtude.

Tal como ocorreu na interação anterior, no entanto, a vítima não aceita conversar de forma calma, visto o estado emocional no qual se encontra. Nesse ponto, o suposto sequestrador desconstrói o ethos de alguém confiável e disposto a fazer o possível para não machucar a suposta sequestrada e passa a utilizar determinados argumentos que procuram coibir a vítima a efetuar o pagamento, construindo, destarte, um ethos amedrontador e mesmo cruel, um ethos de potência:

\section{Excerto IV \\ Suposto Sequestrador: Eu estou falando pra senhora: se a senhora começar a gritar e não conversar direito... Até agora eu estou sendo até um pouco simpático, conversando na moral! Se começar com gritaiada, eu vou desligar e matar a Fernanda!}

Como podemos ver, antes de ameaçar de forma explícita, o sujeito comunicante afirma que estava sendo "um pouco simpático" e "conversando na moral", ou seja, ele constrói para si o ethos dito de alguém simpático, polido e disposto a fazer o melhor possível para resolver a situação sem ferir a filha da vítima. Logo em seguida, no entanto, o sujeito comunicante desconstroi esse ethos, passando a se mostrar como alguém capaz de cometer o assassinato, conforme havia sido ameaçado.

Através da análise dos excertos anteriores, notamos, portanto, que, nos chamados golpes do falso sequestro, os supostos sequestradores constroem para si alguns ethé que buscam corroborar os argumentos utilizados por eles a fim de fazer com que as vítimas efetuem os pagamentos dos falsos resgates. Tais ethé são ancorados em determinados imaginários sociodiscursivos relacionados à violência e criminalidade urbana. 
Dessa forma, os ethé de potência, de criminosos cruéis, dispostos a retirar a vida do suposto sequestrado, ou mesmo tentativas de construção de ethé de virtude, de sujeitos benevolentes e confiáveis, são utilizados pelos supostos sequestradores a fim de que sua finalidade comunicativa (o convencimento das vítimas e, por fim, o pagamento do falso resgate) seja consolidada.

A partir do momento em que este trabalho procura descrever e analisar uma ação possivelmente criminosa praticada pelo telefone, buscando uma melhor compreensão acerca de sua natureza linguístico-discursiva, nossa pesquisa se vincula à Linguística Forense. Com o mapeamento dessas práticas discursivas, é possível que determinadas políticas de segurança pública venham a ser consolidadas, buscando a prevenção a esses golpes que, ainda hoje, são efetuados frequentemente.

Ou seja, acreditamos que a Análise do Discurso pode contribuir de maneira significativa para os estudos em Criminologia e Segurança Pública. Essas reflexões, no entanto, serão mais bem construídas em trabalhos futuros.

\section{Considerações finais}

Notamos, no presente trabalho, que, nas tentativas de crimes de extorsão conhecidas como golpes do falso sequestro, os sujeitos comunicantes que se passam por supostos sequestradores constroem para si o ethos de potência, de alguém cruel, disposto a cometer o assassinato do familiar supostamente sequestrado caso a vítima não efetue o pagamento do resgate. Ao fazerem uso de vocábulos como "cativeiro", "amarrada", "amordaçada" e "matar", os imaginários sociodiscursivos acerca da criminalidade, compartilhados entre os destinatários (as vítimas) e sua comunidade discursiva, subsidiam o ethos de um possível assassino, o que reforça os ethé mostrados ou ditos construídos pelos supostos sequestradores.

Por vezes, no entanto, a depender da natureza de seu argumento, o sujeito comunicante pode procurar construir a imagem de alguém benevolente, um ethos de virtude. Como vimos, no entanto, tais ethé costumam ser logo descostruídos. A construção e tentativa de manutenção desses diferentes ethé, portanto, têm a finalidade de auxiliar no convencimento das vítimas acerca da veracidade dos argumentos utilizados pelos sujeitos comunicantes, deixando claro que eles estariam aptos a concretizar as ameaças efetuadas.

\section{Referências}

AMOSSY, Ruth. Da noção retórica de ethos à análise do discurso. In: AMOSSY, Ruth (Org.). Imagens de si no discurso: a construção do ethos. São Paulo: Contexto, 2005.

BENVENISTE, Émile. Problemas de Linguística Geral II. Trad. Eduardo Guimarães. Campinas: Pontes, 1989.

CHARAUDEAU, Patrick. Les stéréotypes, c'est bien. Les imaginaires, c'est mieux. In: BOYER, H. Stéréotypage, stéréotypes: fonctionnements ordinnaires et mises en scène. Langue(s), discours. Paris: Harmattan, 2007. v. 4.

CHARAUDEAU, Patrick. Linguagem e discurso: modos de organização. São Paulo: Contexto, 2012.

CHARAUDEAU, Patrick. Discurso político. São Paulo: Contexto, 2015.

COULTHARD, Malcolm; JOHNSON, Alison. An Introduction to Forensic Linguistics: Language in Evidence. New York: Routledge, 2007.

DASCAL, Marcelo. O ethos na argumentação: uma abordagem pragma-retórica. In: AMOSSY, Ruth (Org.). Imagens de si no discurso: a construção do ethos. São Paulo: Contexto, 2005.

LINHARES, Juliana. Terror pelo telefone. Revista Veja, edição 1996. Editora Abril. 2007. Disponível em: <http://veja.abril. com.br/210207/p_038.shtml\#trechos>.Acesso em: 19 jun. 2014.

MAINGUENEAU, Dominique. A propósito do ethos. In: MOTA, Ana Raquel; SALGADO, Luciana (Org.). Ethos Discursivo. São Paulo: Contexto, 2008.

OLSSON, John. Forensic Linguistics. New York: Continuum, 2008 .

RODRIGUES, G. E. Considerações acerca das extorsões realizadas por via telefônica através da simulação de um sequestro. ADPESP - Associação dos Delegados de Polícia do Estado de São Paulo, 2007. Disponível em: <http://adpesp.org. br/artigos_exibe.php?id=39>. Acesso em: 16 jun. 2014

SILVA, Welton Pereira e; MELO, Mônica Santos de Souza. A Análise de Gêneros Discursivos na Linguística Forense: um estudo sobre os Golpes do Falso Sequestro. Gragoatá, v. 20, p. 73-90, 2015.

SILVA, Welton Pereira e; MELO, Mônica Santos de Souza; VALE, Rony Petterson Gomes do. Prosódia e construção de ethé discursivos em crimes via telefone. Fórum Linguístico, v. 14, p. $2745,2017$.

Recebido: $24 / 04 / 2018$

Aprovado: 28/09/2018

(D)WeLton PEREIRA E SILVA <weltonp.silva@hotmail.com>

Professor, Universidade Federal do Rio de Janeiro, Rio de Janeiro, Rio de Janeiro, Brasil. 